\title{
ESTIMATION MODEL OF MECHANICAL PROPERTIES FROM THE COMPRESSIVE STRENGTH VALUES
}

\author{
Anderson Renato Vobornik Wolenski ${ }^{1, \star}$, João Paulo Boff Almeida ${ }^{2}$, André Luís Christoforo ${ }^{2}$, \\ Francisco Antonio Rocco Lahr ${ }^{3}$, Rodrigo Guerra Peixoto
}

\begin{abstract}
To ensure the safety of wooden structures, estimation of wood strength is based on the characteristic strength values. The Brazilian standard (NBR, in Portuguese Norma Brasileira Regulamentadora) 7190 proposes equations to estimate the strength properties with a simplified procedure, which allows obtaining the characteristic values through relations that correlate different mechanical properties. Using these equations, the values of tensile $\left(f_{t 0, \mathrm{k}}\right)$ and shear $\left(f_{\mathrm{v} 0, \mathrm{k}}\right)$ strength can be calculated in a simplified way from the compressive strength $\left(f_{c 0, \mathrm{k}}\right)$ values. In the present work, 36 tropical hardwood species were evaluated for tensile, shear and compressive strength in the direction parallel to the grain, with a total of 1296 experimental measurements, and the precision of the relations defined by the Brazilian standard was assessed using the analysis of variance (ANOVA) method. Two-parameter regression models, based on linear, exponential, logarithmic and geometric functions, were used as an alternative proposal for the estimation of the strength properties. The statistical analysis validated the proposed relations, with the linear $\left(f_{t 0 \mathrm{k}}\right)$ and geometric $\left(f_{\mathrm{v0}, \mathrm{k}}\right)$ regression models being the models of best fit, with the coefficients of determination $\left(\mathrm{R}^{2}\right)$ equal to $63,02 \%$ and $70,15 \%$, respectively. In addition, new simplified equations were suggested. The least squares method was used to determine the optimal coefficient $(\alpha)$ for validation of the Brazilian standard equations. The obtained coefficients validated the tensile strength relationship $\left(f_{\mathrm{t} 0, \mathrm{k}}=f_{\mathrm{c} 0, \mathrm{k}} / 0,77\right)$, but failed to validate the shear strength relationship $\left(f_{\mathrm{v} 0, \mathrm{k}}=\right.$ $\left.0,12 \cdot f_{\mathrm{c} 0, \mathrm{k}}\right)$. In the latter case, the obtained values were significantly higher (up to $91 \%$ higher) when compared to those estimated by the Standard.
\end{abstract}

Keywords: Brazilian hardwood species, compressive strength, regression models, shear strength, tensile strength.

\section{INTRODUCTION}

Considering the importance of mechanical properties in the design of such timber structures as bridges, sheds and houses (Ruelle et al. 2011, Dadzie and Amoah 2015), it is of great relevance to evaluate the normative documents which aim to estimate the strength properties of species used in construction. In Brazil, the timber structures have an elevated applicability potential due to a vast number of wood species existing in the Amazonian rainforest. According to Steege et al. (2016), by 2015 there were already discovered more than 10000 wood species. This number induces development of new research aiming at characterization of species that can potentially substitute those that already are commonly used in construction.

The standard ABNT NBR 7190 (1997) regulates the use of timber in construction in Brazil and establishes

\footnotetext{
${ }^{1}$ Department of Civil Engineering, Federal Institute of Santa Catarina (IFSC), São Carlos, Brazil.

${ }^{2}$ Department of Civil Engineering, Federal University of São Carlos (UFSCar), São Carlos, Brazil.

${ }^{3}$ Department of Structural Engineering, University of São Paulo (USP), São Carlos, Brazil.

${ }^{4}$ Department of Structural Engineering, Federal University of Minas Gerais (UFMG), Belo Horizonte, Brazil.

•Corresponding author: anderson.wolenski@ifsc.edu.br

Received: 15.03.2019 Accepted: 20.06.2020
} 
the requirements for project development, construction and control of wooden structures, basing on probabilistic methods, which assess fracture strength, instability, excessive deformation, and durability of the structure. The Standard also specifies the complete, minimal and simplified characterization methods of wood physical and mechanical properties. This is justified by anatomic structure of wood, distinct for each species. For the characterization of wood, the loading type, grain direction and moisture content shall be taken into account.

Examination of the equations that estimate the mechanical properties of the species used in construction is of great importance. Such equations are determined in the Brazilian standard ABNT NBR 7190 (1997) defining the simplified characterization method, which allows obtaining different strength properties of common wood species when experimental data are not available. Nevertheless, Logsdon et al. (2010) stress that this simplified method should not be the only rule for determination of characteristic wood properties. These authors sought to benchmark a model for characteristic compressive strength $\left(f_{\mathrm{c} 0 \mathrm{k}}\right)$ estimation, aiming to obtain a more appropriate statistical model for Dinizia excelsa Ducke species. They have concluded that NBR equation is more conservative as it provides slightly lower $f_{\mathrm{c} 0, \mathrm{k}}$ values. Similarly Matos and Molina (2016) investigated a correlation between the compressive and shear strength $\left(f_{\mathrm{c} 0, \mathrm{k}}\right.$ and $\left.f_{\mathrm{v} 0, \mathrm{k}}\right)$ of Pinus elliotti and Corymbia citriodora species, comparing an experimental relation with the standardized relations of ABNT NBR 7190 (1997) and ISO 13910 (2005), and concluded that for both species the values obtained from the relations of the Brazilian standard were higher than obtained by the equations of the European standard.

Longui et al. (2017) tested four Brazilian wood species for the shear strength parallel to the grain. The researchers evaluated the shear in specimens with distinct ray orientation, and concluded that there was no statistically significant difference between the specimens with rays oriented parallel to the shear plane and the specimens having perpendicular and diagonal ray orientation with respect to the shear plane. Recently, Christoforo et al. (2019a) used the probability models to evaluate the ABNT NBR 7190 (1997) equations of the characteristic values $\left(f_{\mathrm{t} 0 \mathrm{k}}, f_{\mathrm{v} 0 \mathrm{k}}\right.$ and $\left.f_{\mathrm{c} 0 \mathrm{k}}\right)$ for five tropical wood species. The obtained values were significantly higher (up to $92 \%$ higher) than the values estimated by the Brazilian standard.

These previous studies demonstrate the importance of assessing the physical and mechanical properties of wood in order to obtain reliable and safe estimates for structural dimensioning. Several authors already investigated some of the hardwood species that are studied in the present work, however, focusing on physical and mechanical properties of only few species: Mezilaurus itauba (Silva et al. 2014), Hymenaea sp (Icimoto et al. 2015, Segundinho et al. 2015), Apuleia leiocarpa (Soriano et al. 2015), Cedrela odorata (Fernandes et al. 2018), and Peltophorum vogelianum (Christoforo et al. 2019b).

The applicability of the researches seeking equations that estimate the mechanical properties of distinct species for structural use is remarkable. A need for such estimates motivated the present work, in which 36 hardwood species were assessed. The ABNT NBR 7190 (1997) presents average values of physical and mechanical properties of 43 species of native and afforestation woods, and this set is similar to the species evaluated in the present study, thus reinforcing the reliability of the statistical analyses carried out here for tropical hardwood species of Brazilian forests.

\section{MATERIALS AND METHODS}

In this work, homogeneous batches were used in all the tests, as it is required by ABNT NBR 7190 (1997). According to the Standard, the batch volume cannot exceed $12 \mathrm{~m}^{3}$, and the specimens should be extracted randomly, limited to one sample per beam, as shown in Figure 1. All wood species were stored and tested at the LaMEM (Laboratório de Madeiras e Estruturas de Madeiras) of the University of São Paulo (USP), following the procedures of Brazilian standard. 


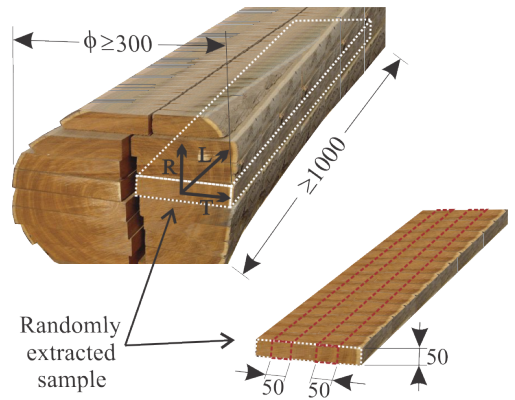

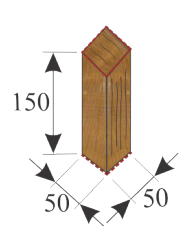

(a)

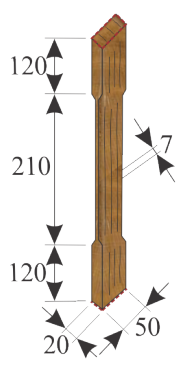

(b)

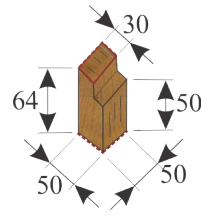

(c)

Figure 1: Sample extraction and size (in $\mathrm{mm}$ ) for determination of compressive (a), tensile (b), and shear (c) mechanical properties.

Thirty-six tropical hardwoods were tested in this study (Table 1). The timber was obtained from local companies in the same manner as it is obtained for civil construction in Brazil: in the form of boards extracted from the heartwood (Figure 1), therefore, it was not possible to identify origin and age of the trees. It should be noted that for each test and tropical hardwood species, 12 specimens were confectioned, resulting in a total of 1296 experimental measurements.

Table 1: Scientific name and identification number (ID) of 36 tropical hardwoods.

\begin{tabular}{|c|c|c|c|c|c|}
\hline ID & Hardwood species & ID & Hardwood species & ID & Hardwood species \\
\hline 1 & Vatairea fusca & 13 & Cedrelinga catenaeformis Ducke & 25 & Qualea paraensis Ducke \\
\hline 2 & Hymenolobium sp & 14 & Copaifera multijuga Hayne & 26 & Clarisia racemosa \\
\hline 3 & Vatairea sp & 15 & Goupia paraensis Hub. & 27 & Pradosia Liais \\
\hline 4 & Dinizia excelsa Ducke & 16 & Apuleia leiocarpa & 28 & Parinari rodolph Huber \\
\hline 5 & Anadenanthera colubrina & 17 & Planchonella pachycarpa Pires & 29 & Copaifera langsdorffii Desf. \\
\hline 6 & Sebastiania commersoniana (Baill.) S. \& D. & 18 & Luetzelburgia sp & 30 & Tapirira guianensis Aubl. \\
\hline 7 & Cassia ferruginea & 19 & Peltophorum vogelianum Benth. & 31 & Erisma uncinatum Warm. \\
\hline 8 & Bertholletia excels Bonpl. & 20 & Mezilaurus itauba & 32 & Cinchona sp \\
\hline 9 & Gossypiospermum praecox & 21 & Hymenaea sp & 33 & Vochysia sp \\
\hline 10 & Calophyllum sp & 22 & Ocotea sp & 34 & Pterodon emarginatus \\
\hline 11 & Cedrela odorata Lin. & 23 & Laurus nobilis & 35 & Tachigali myrmecophila Ducke \\
\hline 12 & Cedrela sp & 24 & Manilkara huberi (Ducke) Standl. & 36 & Qualea retusa \\
\hline
\end{tabular}

Mechanical strength values $f_{\mathrm{c} 0}, f_{\mathrm{t} 0}$ and $f_{\mathrm{v} 0}$ were obtained in the direction parallel to the grain, with a monotonously increasing load at the rate of $10 \mathrm{MPa} / \mathrm{min}$. To calculate the values, Equation 1 was used, where $F_{w 0, \text { max }}$ is a maximal load applied on the specimens and $A$ is an initial cross-sectional area of compressive (Figure 1a) and tensile (Figure 1b) specimens and critical cross-section area for shear specimens (Figure 1c).

$$
f_{w o}=\frac{F_{w 0, \max }}{A}(1)
$$

Mechanical strength values $\left(f_{\mathrm{c} 0}, f_{\mathrm{t} 0}\right.$ and $\left.f_{\mathrm{v} 0}\right)$ were adjusted for $12 \%$ moisture level using Equation 2 , as prescribed by the ABNT NBR 7190 (1997), where $12 \%$ is the moisture level provided by this document.

$$
f_{12 \%}=f_{U \%}\left[1+\frac{3(U \%-12)}{100}\right]
$$


where $f_{12 \%}$ and $f_{U \%}$ values correspond, respectively, to moisture levels of $12 \%$ and $\mathrm{U} \%$.

The characteristic values of the evaluated properties $\left(f_{\mathrm{t} 0}\right.$ and $f_{\mathrm{v} 0}$ as a function of $\left.f_{\mathrm{c} 0}\right)$ can be calculated from 12 values obtained for each species, following the recommendation of the Brazilian standard ABNT NBR 7190 (1997). The Equation 3 gives the characteristic strength value $\left(f_{\mathrm{w}, \mathrm{k}}\right)$ corresponding to the $5 \%$ percentile of the distribution of strength values:

$$
f_{w, k}=f_{m}[1-1,645 \delta]
$$

where $f_{\mathrm{m}}$ is the average strength value and $\delta$ is the coefficient of variation.

In addition, the ABNT NBR 7190 (1997) requires that the dimensioning of the wooden structures is done on the linear kinematic hypothesis (allowing small displacements). For safety reasons the probabilistic methodology of the Standard supposes that the strength values are normally distributed, and the coefficient of variation is $\delta=18 \%$ for tensile and compressive strength, as given by Equation 4 .

$$
f_{w, k}=f_{m}[1-1,645 \delta] \approx 0,70 f_{m}
$$

On the other hand, for the direct strength estimation, the Standard provides Equation 5, which gives the $f_{\mathrm{w}, \mathrm{k}}$ value as following:

$$
f_{w, k}=\left[2 \frac{f_{1}+f_{2}+f_{3}+\ldots+f_{(n / 2)-1}}{(n / 2)-1}-f n / 2\right] 1,10
$$

where $f_{\mathrm{n}}$ is $n$ determined strength values, arranged in the ascending order $\left(f_{1}<f_{2}<f_{3}<\ldots<f_{\mathrm{n}}\right)$; if the number of the specimens is odd, the highest value is disregarded. The equation is based on the estimator $z_{b}$ (Equation $6)$, for the sample of $2 m$ values $x_{1}+x_{2}+x_{3}+\ldots+x_{2 m}$.

$$
z_{b}=\left[2 \frac{x_{1}+x_{2}+x_{3}+\ldots+x_{(m-1)}}{(m-1)}-f_{m}\right]
$$

However, for the distribution centered on the characteristic value, there is a $10 \%$ increase added to Equation 5, which, according to Logsdon et al. (2010), allows avoiding that $50 \%$ of the estimates is done by the values below the characteristic strength.

On the basis of these equations, $f_{\mathrm{w}, \mathrm{k}}$ is given as the highest value among: the strength less than $f_{1}$, the strength less than $70 \%$ of $f_{\mathrm{m}}$ (Equation 5 ) obtained from the tested specimens, and the value computed by Equation 3, according to ABNT NBR 7190 (1997).

The obtained characteristic values (Equation 4) can then be used to assess the expressions defined in the Brazilian standard for a simplified characterization of the wood basing on the compressive strength in the direction parallel to the grain $\left(f_{\mathrm{c} 0}\right)$. The Standard provides some relations, in particular Equation 7 and Equation 8 , which allow obtaining the strength characteristics $f_{\mathrm{t} 0, \mathrm{k}}$ and $f_{\mathrm{v} 0, \mathrm{k}}$ from $f_{\mathrm{c} 0, \mathrm{k}}$ :

$$
\begin{aligned}
f_{t 0, k} & =\frac{f_{c 0, k}}{0,77} \\
f_{v 0, k} & =0,12 f_{c 0, k}
\end{aligned}
$$


These equations were used to determine the mechanical properties in this work. The simplification found in these equations may (or may not) be consistent with the actual results of the experiments; therefore, this work sought to evaluate the applicability of regression models for estimation of the mechanical parameters $\left(f_{\mathrm{t} 0, \mathrm{k}}\right.$ and $f_{\mathrm{v} 0, \mathrm{k}}$ from $\left.f_{\mathrm{c} 0, \mathrm{k}}\right)$.

The experimentally obtained strength values were fit into Equation 9, Equation 10, Equation 11 and Equation 12 to verify if any of the regression models (linear, exponential, logarithmic or geometric) can be used for estimation the strength values:

$$
\begin{array}{lc}
y=a+b x & (\text { linear }) \\
y=a e^{b x} \quad(\text { exponential }) \\
y=a+b \ln (x) & \quad(\text { logarithmic }) \\
y=a x^{b} \quad(\text { geometric })
\end{array}
$$

where:

$y$ is a dependent variable,

$x$ is an independent variable,

$a$ and $b$ are parameters of the model, obtained by the least squares method.

The analysis of variance (ANOVA) and the Tukey Method were used to determine the equivalence of strength values estimated by the models and those experimentally obtained (with the significance level set to 0,05). The normality of distribution was tested using Anderson-Darling test (Weerahandi 1995), and the significance level was also set to 0,05 . In the Tukey Method, "A" denotes the group with the highest mean value, "B" the group with the second highest mean value, and equal letters correspond to statistically equivalent means. Finally, the coefficient of determination $\left(\mathrm{R}^{2}\right)$ was used as a criterion to determine the regression model of best fit.

In addition, the least squares method (Equation 13 and Equation 14) was used to determine the optimal coefficient $(\alpha)$ of the relationships between the characteristics values $\left(f_{\mathrm{t} 0, \mathrm{k}}=f_{\mathrm{c} 0, \mathrm{k}} / \alpha\right.$ and $\left.f_{\mathrm{v} 0, \mathrm{k}}=\alpha \cdot f_{\mathrm{c} 0, \mathrm{k}}\right)$. The Newton method was used with a quadratic approximation (Equation 15) and convergence for optimal solution independent of the initial estimate $\left(\alpha_{0}\right)$ in the iterative method.

$$
\begin{aligned}
& f(\alpha)=\frac{1}{2} \sum_{i=1}^{n}\left(f_{c 0, k_{i}}-\alpha_{f t 0, k_{i}}\right)^{2} \\
& f(\alpha)=\frac{1}{2} \sum_{i=1}^{n}\left(f_{v 0, k_{i}}-\alpha_{f c 0, k_{i}}\right)^{2} \\
& \alpha=\alpha_{0}-\left(\frac{d^{2}}{d \alpha^{2}}\left[f\left(\alpha_{0}\right)\right]\right)^{-1} \frac{d}{d \alpha}\left[f\left(\alpha_{0}\right)\right]
\end{aligned}
$$

The evaluation of the expressions proposed by the Brazilian standard (Equations 7 and Equation 8), therefore, can be alternatively done using the regression functions (Equations 7, Equation 8, Equation 9 and Equation 10). The coefficient $\alpha$ (Equation 15), together with the ANOVA, the normality test and the Tukey Method, can be used to validate the relationships given in the NBR. 


\section{RESULTS AND DISCUSSION}

Figure 2 shows the average values, confidence intervals (at the $95 \%$ confidence level), and the ranges (maximum and minimum values) of variance of the coefficient of variation $(\mathrm{CV})$ of the strength properties, $f_{\mathrm{t} 0}$ (a), $f_{\mathrm{v} 0}(\mathrm{~b})$ and $f_{\mathrm{c} 0}$ (c) for the 36 investigated hardwoods.

To the $f_{\text {t0 }}$ strength (Figure 2a) most species reached coefficients of variation above of the values recommended by the Brazilian standard (18\% for normal stresses). The ranges of variance were equal the $\mathrm{CV}(\%)=$ $(12,60 ; 38,10)$. The high values of this coefficient can be explained by its rupture mode, justified in parts for anatomical reasons of the wood. Only the species Anadenanthera colubrina (15,5\%), Calycophyllum multiflorum Griseb. (14,8 \%), Peltophorum vogelianum Benth. (17,3\%), Ocotea sp (17,9\%), Laurus nobilis (12,6 $\%)$, and Clarisia racemosa (14,9\%) reached values for the coefficient as expected.

Already to the $f_{\mathrm{v} 0}$ strength (Figure 2b), all hardwood species reached coefficients of variation in accordance with those refereed ( $28 \%$ for tangential stresses) by the Brazilian standard. The ranges of variance were equal the $\mathrm{CV}(\%)=(7,0 ; 28,0)$.

The coefficients of variation to the $f_{\mathrm{c} 0}$ strength (Figure $2 \mathrm{c}$ ) reached those referenced (18\% for normal stresses) by the Brazilian standard with ranges of variance equal the $\mathrm{CV}(\%)=(4,40 ; 25,40)$. However, to some species this limit was exceeded: Cassia ferruginea (18,9\%), Cedrelinga catenaeformis Ducke (22,8 \%), Qualea paraensis Ducke (19,7 \%), Vochysia sp (19,9\%), Erisma uncinatum Warm. (25,4 \%), and Tapirira guianensis Aubl. (21,6\%).
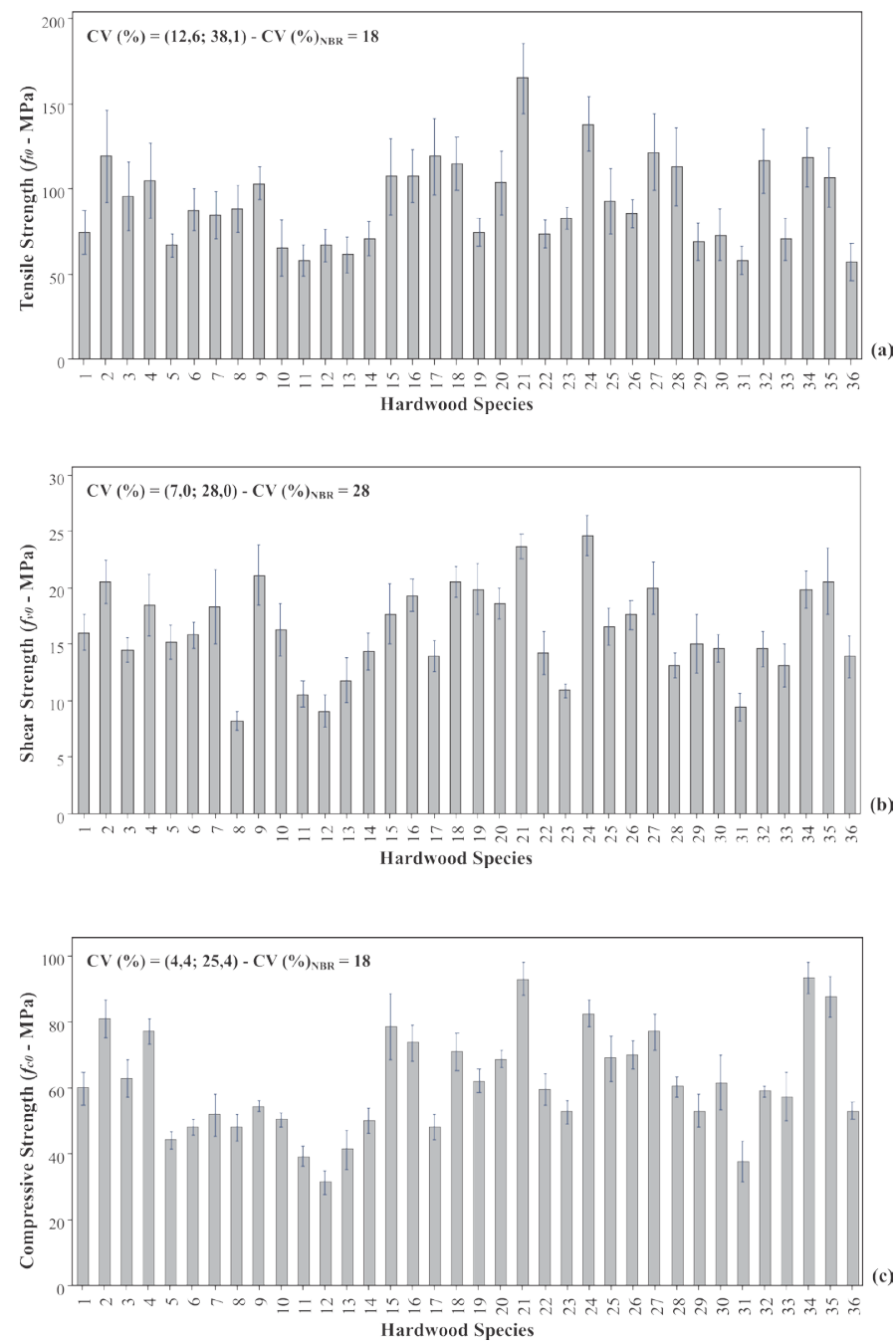

Figure 2: Results of the tensile (a), shear (b) and compressive (c) strength of the 36 hardwood species. 
Table 2 shows experimentally obtained tensile, shear and compressive strength values for 36 species of tropical hardwood. Comparison of the values presented in Table 2 with the values found in ABNT NBR 7190 (1997) demonstrates the agreement of the experimental results with the values registered in the Standard.

Table 2: Descriptive statistics of experimentally obtained values (in MPa) for 36 tropical hardwoods.

\begin{tabular}{|c|c|c|c|c|c|c|c|c|c|c|c|}
\hline \multirow[b]{2}{*}{ ID } & \multicolumn{3}{|c|}{ Experimental Values } & \multicolumn{2}{|c|}{ Estimated Values } & \multirow[b]{2}{*}{ ID } & \multicolumn{3}{|c|}{ Experimental Values } & \multicolumn{2}{|c|}{ Estimated Values } \\
\hline & $f_{c o, k}$ & $f_{t, t, k}$ & $f_{v 0, k}$ & $\begin{array}{c}f_{t, k, k} \\
(\mathrm{Eq} \cdot 7)\end{array}$ & $\begin{array}{c}\boldsymbol{f}_{v 0, k} \\
(\mathrm{Eq} \cdot 8)\end{array}$ & & $f_{c o, k}$ & $f_{t, k}$ & $f_{v o, k}$ & $\begin{array}{c}f_{t, 0, k} \\
(\mathrm{Eq} \cdot 7)\end{array}$ & $\begin{array}{c}\boldsymbol{f}_{\boldsymbol{v}, \boldsymbol{k}, \boldsymbol{k}} \\
(\mathrm{Eq} \cdot 8)\end{array}$ \\
\hline 1 & 47,52 & 52,56 & 12,76 & 61,71 & 5,70 & 19 & 56,34 & 63,98 & 17,47 & 73,17 & 6,76 \\
\hline 2 & 76,03 & 83,51 & 17,20 & 98,74 & 9,12 & 20 & 68,44 & 72,60 & 16,32 & 88,89 & 8,21 \\
\hline 3 & 51,06 & 67,12 & 12,10 & 66,31 & 6,13 & 21 & 89,96 & 125,29 & 23,08 & 116,83 & 10,80 \\
\hline 4 & 72,73 & 77,02 & 13,35 & 94,46 & 8,73 & 22 & 50,60 & 61,36 & 10,40 & 65,71 & 6,07 \\
\hline 5 & 41,87 & 53,94 & 12,72 & 54,38 & 5,02 & 23 & 49,14 & 69,87 & 9,77 & 63,82 & 5,90 \\
\hline 6 & 45,58 & 67,20 & 13,75 & 59,20 & 5,47 & 24 & 79,46 & 109,40 & 20,77 & 103,20 & 9,54 \\
\hline 7 & 36,37 & 59,44 & 12,97 & 47,24 & 4,36 & 25 & 61,53 & 65,13 & 14,34 & 79,91 & 7,38 \\
\hline 8 & 38,93 & 61,95 & 7,04 & 50,56 & 4,67 & 26 & 62,41 & 74,23 & 15,18 & 81,06 & 7,49 \\
\hline 9 & 54,54 & 86,42 & 15,55 & 70,83 & 6,54 & 27 & 72,34 & 85,29 & 14,63 & 93,94 & 8,68 \\
\hline 10 & 50,91 & 48,79 & 12,30 & 66,12 & 6,11 & 28 & 55,22 & 79,35 & 12,01 & 71,71 & 6,63 \\
\hline 11 & 33,18 & 44,04 & 8,56 & 43,09 & 3,98 & 29 & 45,06 & 50,30 & 10,62 & 58,51 & 5,41 \\
\hline 12 & 29,99 & 48,55 & 7,13 & 38,94 & 3,60 & 30 & 43,74 & 51,13 & 12,39 & 56,80 & 5,25 \\
\hline 13 & 29,06 & 50,07 & 8,37 & 37,74 & 3,49 & 31 & 27,20 & 40,63 & 6,70 & 35,33 & 3,26 \\
\hline 14 & 44,13 & 52,67 & 10,25 & 57,31 & 5,30 & 32 & 61,60 & 81,65 & 11,37 & 80,00 & 7,39 \\
\hline 15 & 55,28 & 75,22 & 12,63 & 71,79 & 6,63 & 33 & 44,79 & 51,36 & 9,30 & 58,17 & 5,38 \\
\hline 16 & 65,36 & 81,62 & 16,28 & 84,89 & 7,84 & 34 & 90,46 & 83,43 & 17,42 & 117,49 & 10,86 \\
\hline 17 & 43,10 & 83,54 & 12,14 & 55,97 & 5,17 & 35 & 75,46 & 74,73 & 14,54 & 98,00 & 9,06 \\
\hline 18 & 58,92 & 80,59 & 17,51 & 76,51 & 7,07 & 36 & 51,28 & 39,99 & 9,83 & 66,60 & 6,15 \\
\hline
\end{tabular}

$f_{c o, k}-$ characteristic compressive strength parallel to the grain; $f_{t 0, k}$ - characteristic tensile strength parallel to the grain; $f_{v 0, k}$ - characteristic shear strength parallel to the grain.

ANOVA was used to compare the 36 experimentally obtained results of $f_{\mathrm{t} 0, \mathrm{k}}$ and $f_{\mathrm{v} 0, \mathrm{k}}$ (Table 1 , experimental values) to $f_{\mathrm{t} 0, \mathrm{k}}$ and $f_{\mathrm{v} 0, \mathrm{k}}$ values calculated from experimental $f_{\mathrm{c} 0, \mathrm{k}}$ values (Table 1, experimental values) using the Equation 7 and Equation 8 (Table 1, estimated values).

Tables 3 and Table 4, and Figure 2 show, respectively, the results of ANOVA, the Tukey method, and the normality test of Anderson-Darling, with the aim to evaluate the Equation 7.

Table 3: Results of ANOVA on the sample sets: $f_{\mathrm{t} 0, \mathrm{k}}$ (experimental values) and $f_{\mathrm{t} 0, \mathrm{k}}$ (Equation 7).

\begin{tabular}{|c|c|c|c|c|c|}
\hline Source & $\mathbf{G L}$ & $\mathbf{S Q}_{\mathrm{AJ}}$ & $\mathbf{Q M}_{\mathbf{A J}}$ & Value-F & P-Value \\
\hline Condition & 1 & 114,9 & 114,9 & 0,29 & 0,591 \\
\hline Error & 70 & 27585,3 & 394,1 & -- & -- \\
\hline Total & 71 & 27700,2 & -- & -- & -- \\
\hline
\end{tabular}

DOFs - Degrees of Freedom; $\mathrm{SQ}_{\mathrm{AJ}}$ - sum of squares; $\mathrm{QM}_{\mathrm{AJ}}$ - average squares. 
Table 4: Grouping information using the Tukey Method and $95 \%$ of confidence level for $f_{\mathrm{t} 0, \mathrm{k}}$.

\begin{tabular}{|c|c|c|c|c|c|}
\hline Source & $\mathbf{N}$ & Mean & StDev & $\mathbf{9 5} \% \mathbf{C I}$ & Grouping * \\
\hline$f_{\mathrm{t} 0, \mathrm{k}}($ experimental values) & 36 & 70,69 & 21,00 & $(64,09 ; 77,29)$ & $\mathrm{A}$ \\
\hline$f_{\mathrm{t} 0, \mathrm{k}}$ (Eq. 7) & 36 & 68,17 & 18,64 & $(61,57 ; 74,77)$ & $\mathrm{A}$ \\
\hline
\end{tabular}

* Means with distinct letters are significantly different.

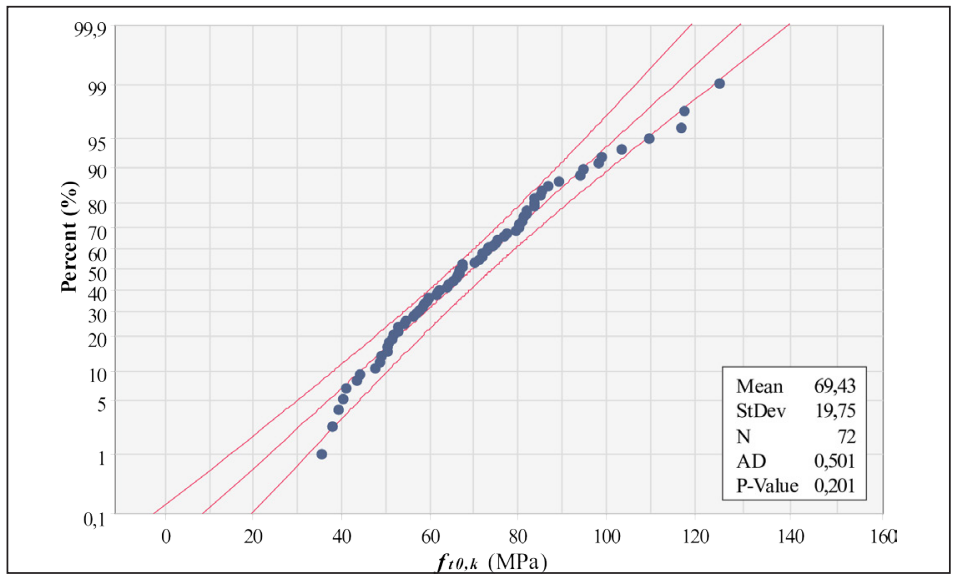

Figure 3: Results of ANOVA validation: normality test of Anderson-Darling for Equation 7.

It can be seen that the compared groups of values - $f_{t 0, \mathrm{k}}$ (experimental values) and $f_{\mathrm{t} 0, \mathrm{k}}$ (Equation 7) - are equivalent (P-Value=0,591, Table 3), indicating the accuracy of Equation 7 proposed by the ABNT NBR 7190 (1997). Figure 3 confirms the results of ANOVA with the normality test of Anderson-Darling and P-Value $=0,201$.

Similarly, Table 5 and Table 6, and Figure 4 show, respectively, the results of ANOVA and the Tukey Method test for evaluation of the Equation 8.

Table 5: Results of ANOVA on the sample sets: $f_{\mathrm{v} 0, \mathrm{k}}$ (experimental values) and $f_{\mathrm{v} 0, \mathrm{k}}$ (Equation 8).

\begin{tabular}{|c|c|c|c|c|c|}
\hline Source & $\mathbf{G L}$ & $\mathbf{S Q}_{\mathrm{AJ}}$ & $\mathbf{Q M}_{\mathbf{A J}}$ & Value-F & P-Value \\
\hline Condition & 1 & 758,00 & 757,96 & 85,14 & 0,000 \\
\hline Error & 70 & 623,10 & 8,90 & -- & -- \\
\hline Total & 71 & 1381,10 & -- & -- & -- \\
\hline
\end{tabular}

DOFs - Degrees of Freedom; $\mathrm{SQ}_{\mathrm{AJ}}$ - sum of squares; $\mathrm{QM}_{\mathrm{AJ}}$ - average squares.

Table 6: Grouping information using the Tukey Method and $95 \%$ of confidence level for $f_{\mathrm{v} 0, \mathrm{k}}$.

\begin{tabular}{|c|c|c|c|c|c|}
\hline Source & $\mathbf{N}$ & Mean & StDev & $\mathbf{9 5} \%$ CI & Grouping * \\
\hline$f_{\mathrm{v} 0, \mathrm{k}}($ experimental values) & 36 & 13,021 & 3,747 & $(12,03 ; 14,01)$ & $\mathrm{A}$ \\
\hline$f_{\mathrm{v} 0, \mathrm{k}}$ (Eq. 8) & 36 & 6,532 & 1,940 & $(5,540 ; 7,524)$ & $\mathrm{B}$ \\
\hline
\end{tabular}

* Means with distinct letters are significantly different. 


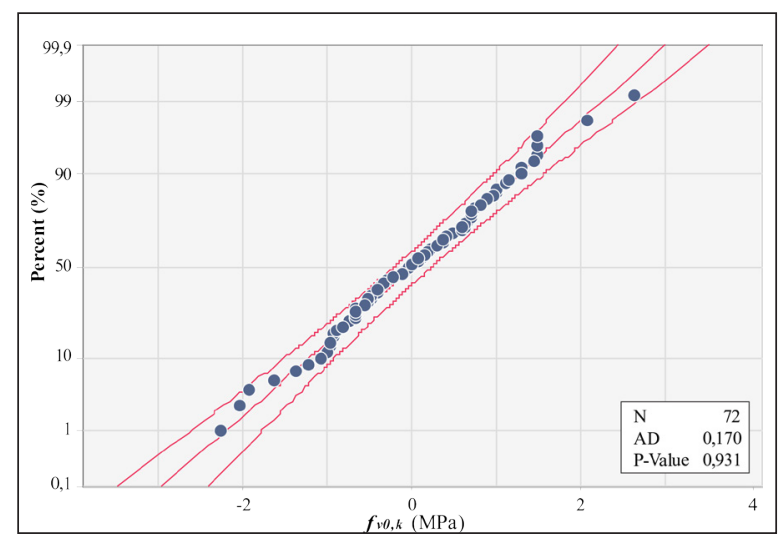

Figure 4: Probability plot for transformed data for Equation 8.

It can be seen that the compared groups of values - $f_{\mathrm{v} 0, \mathrm{k}}$ (experimental values) and $f_{\mathrm{v} 0 . \mathrm{k}}$ (Equation 8 ) - are not equivalent (P-Value $=0,00$, Table 5), indicating an inaccuracy of Equation 8 of the ABNT NBR 7190 (1997). Figure 4 confirms the results of ANOVA for a normal distribution of data and P-Value $=0,931$.

Alternatively, Table 7 and Figure 5 present regression models for estimation of $f_{\mathrm{t} 0, \mathrm{k}}$ values from $f_{\mathrm{c} 0 \mathrm{k}}$ values for 36 examined hardwood species. $\mathrm{P}$-value allows evaluating the applicability $(\mathrm{P}<0,05)$ or non-applicability $(\mathrm{P}>0,05)$ of the regression model.

Table 7: Results for regression models estimating the mechanical properties: $f_{\mathrm{t} 0, \mathrm{k}}$ from $f_{\mathrm{c} 0, \mathrm{k}}$.

\begin{tabular}{|c|c|c|c|c|c|}
\hline Models & Equations & $\boldsymbol{a}$ & $\boldsymbol{b}$ & P-Value & $\boldsymbol{R}^{2}(\%)$ \\
\hline Linear & $f_{\mathrm{t} 0, \mathrm{k}}=a+b \cdot\left(f_{\mathrm{c} 0, \mathrm{k}}\right)$ & $\mathbf{1 8 , 4}$ & $\mathbf{0 , 9 2}$ & $<\mathbf{0 , 0 0 0 0 1}$ & $\mathbf{6 3 , 0 2}$ \\
\hline Exponential & $f_{\mathrm{t} 0, \mathrm{k}}=a+e^{b \cdot\left(\mathrm{f}^{\mathrm{k}, \mathrm{k}}\right)}$ & 32,4 & 0,013 & $<0,00001$ & 62,20 \\
\hline Logarithmic & $f_{\mathrm{t} 0, \mathrm{k}}=a+b \cdot \ln \left(f_{\mathrm{c} 0, \mathrm{k}}\right)$ & -118 & 47,1 & $<0,00001$ & 59,37 \\
\hline Geometric & $f_{\mathrm{t} 0, \mathrm{k}}=a \cdot\left(f_{\mathrm{c} 0, \mathrm{k}}\right)^{b}$ & 0,69 & 4,33 & $<0,00001$ & 61,20 \\
\hline
\end{tabular}

$f_{c 0, k}$ - characteristic compressive strength parallel to the grain; $f_{t 0, k}$ - characteristic tensile strength parallel to the grain; $\mathrm{R}^{2}$ - coefficient of determination; and - constant of the regression models.

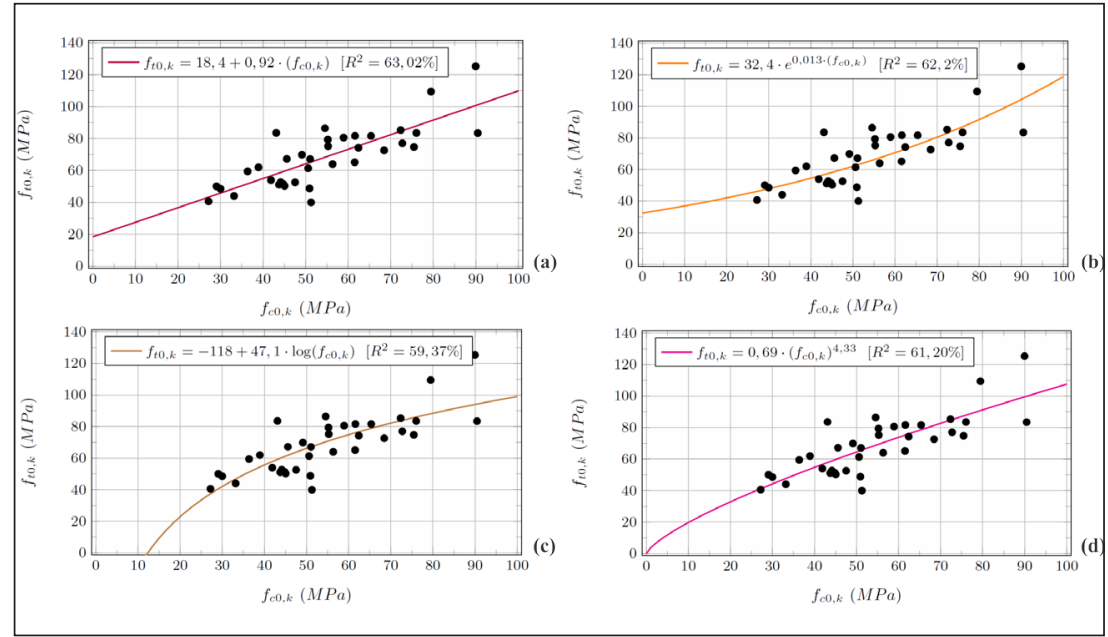

Figure 5: Regression models for the characteristic value of tensile strength $\left(f_{t 0, k}\right)$ : Linear (a); Exponential (b); Logarithmic (c) and Geometric (d). 
Similarly, Table 8 and Figure 6 present regression models for estimation of $f_{\mathrm{v} 0, \mathrm{k}}$ values from $f_{\mathrm{c} 0, \mathrm{k}}$ values for the examined species.

Table 8: Results for regression models estimating the mechanical properties: $f_{\mathrm{v} 0, \mathrm{k}}$ from $f_{\mathrm{c} 0, \mathrm{k}}$.

\begin{tabular}{|c|c|c|c|c|c|}
\hline Models & Equations & $\boldsymbol{a}$ & $\boldsymbol{b}$ & P-Value & $\boldsymbol{R}^{2}(\%)$ \\
\hline Linear & $f_{\mathrm{v} 0, \mathrm{k}}=a+b \cdot\left(f_{\mathrm{c} 0, \mathrm{k}}\right)$ & 2,55 & 0,19 & $<0,00001$ & 68,88 \\
\hline Exponential & $f_{\mathrm{v} 0, \mathrm{k}}=a+e^{b \cdot\left(f_{0} 0, \mathrm{k}\right)}$ & 5,53 & 0,015 & $<0,00001$ & 67,48 \\
\hline Logarithmic & $f_{\mathrm{v} 0, \mathrm{k}}=a+b \cdot \ln \left(f_{\mathrm{c} 0, \mathrm{k}}\right)$ & $-27,05$ & 10,14 & $<0,00001$ & 67,52 \\
\hline Geometric & $\boldsymbol{f}_{\mathbf{v} 0, \mathbf{k}}=\boldsymbol{a} \cdot\left(f_{\mathrm{c} \mathbf{0}, \mathrm{k}}\right)^{b}$ & $\mathbf{0 , 5 0}$ & $\mathbf{0 , 8 1}$ & $<\mathbf{0 , 0 0 0 0 1}$ & $\mathbf{7 0 , 1 5}$ \\
\hline
\end{tabular}

$f_{c \theta, k}$ - characteristic compressive strength parallel to the grain; $f_{v 0, k}$ - characteristic shear strength parallel to the grain; $\mathrm{R}^{2}$ - coefficient of determination; and - constant of the regression models.

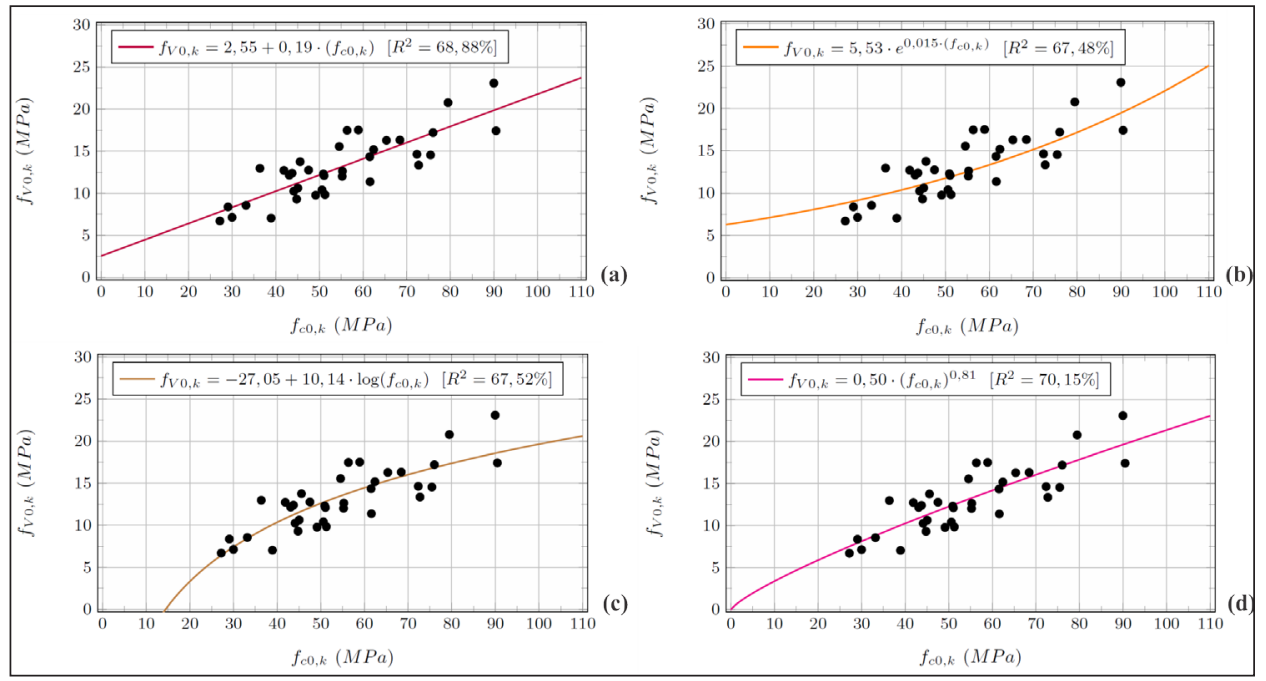

Figure 6: Regression models for the characteristic value of shear strength $\left(f_{\mathrm{v} 0, \mathrm{k}}\right)$ : Linear (a); Exponential (b); Logarithmic (c) and Geometric (d).

From Equation 15, applying Equation 13 and Equation 14, the estimated optimal coefficient values for the tensile and shear strengths were $\alpha=0,79$ and $\alpha=0,23$, respectively. These values were approximately $2 \%$ and $91 \%$ higher than the coefficients proposed by the NBR standard (Equation 7 and Equation 8). This indicates that the coefficients proposed by the Brazilian standard favor the safety of structures. However, the coefficient obtained in the present study for the shear strength was considerably different from the one proposed by Brazilian standard. This value may overestimate the dimensions of the timber structures, affecting directly the final cost of the structure.

Finally, this research presented results for a total of 36 tropical hardwoods, which is a significant addition to the results of similar works done by other authors, expanding the number of species studied by Baar et al. (2015), Longui et al. (2017), Tenorio and Moya (2018), Silva et al. (2018), and Christoforo et al. (2019b). The results suggest that the equations $f_{\mathrm{t} 0, \mathrm{k}}=18,4+0,92 \cdot f_{\mathrm{c} 0, \mathrm{k}}$ (Figure 5a), and $f_{\mathrm{v} 0, \mathrm{k}}=0,50 \cdot\left(f_{\mathrm{c} 0, \mathrm{k}}\right)^{0,81}$ (Figure 6d) are the most adequate for estimation, respectively, of the tensile and shear from compressive strength values.

\section{CONCLUSIONS}

In this paper, 36 tropical hardwood species were experimentally classified employing the procedures of the Brazilian standard for timber structures. The evaluated species demonstrated a potential for application in civil construction and the results have shown that the Brazilian hardwoods tested here are disposed among all the 
strength classes with the range between $20 \mathrm{MPa}$ and $90 \mathrm{MPa}$ of compressive strength in the direction parallel to the grain.

The tensile strength values indicate the accuracy of the equation presented in the Brazilian standard. Alternatively, regression models were proposed in this work, and the linear relationship was considered the model of best fit $\left(\mathrm{R}^{2}=63 \%\right)$ for tensile strength estimation in the direction parallel to the grain. On the other hand, a comparison of shear strength values revealed a significant difference, indicating the weakness of the equation proposed by standard, which reinforces the importance of a revision normative. The geometric regression model was found to be the most appropriate $\left(\mathrm{R}^{2}=70 \%\right)$ for estimation of shear strength from the compressive strength in the direction parallel to the grain.

Lastly, the coefficients of determination $\left(\mathrm{R}^{2}\right)$ demonstrate that the regression models achieved herein are appropriate to estimate the tensile and shear characteristic strength values, from the compressive strength in the direction parallel to the grain for tropical hardwood species, providing an important study to be revised in the standard document ABNT NBR 7190 (1997).

\section{ACKNOWLEDGMENTS}

The authors gratefully acknowledge the important support of the Brazilian research agencies FAPESP (in Portuguese "Fundação de Amparo à Pesquisa de São Paulo") and of CNPq (in Portuguese "Conselho Nacional de Desenvolvimento Científico e Tecnológico"). Authors would also like to thank the LaMEM (in Portuguese "Laboratório de Madeiras e Estruturas de Madeiras"), of the Structural Engineering Department (SET), University of São Paulo (USP) for the supply of materials and resources used in the experimental tests.

\section{REFERENCES}

Baar, J.; Tippner, J.; Rademacher, P. 2015. Prediction of mechanical properties - modulus of rupture and modulus of elasticity of five tropical species by nondestructive methods. Maderas-Cienc Tecnol 17(2): 239-252. http://dx.doi.org/10.4067/S0718-221X2015005000023.

Christoforo, A.L.; Almeida, A.S.; Lanini, T.L.S.; Nogueira, R.S.; Lahr, F.A.R. 2019a. Estimation of the characteristic value of wood strength. Eng Agr-Jaboticabal 39(1): 127-132. https://doi.org/10.1590/18094430-eng.agric.v39n1p127-132/2019.

Christoforo, A.L.; Aquino, V.B.M.; Wolenski, A.R.V.; Araujo, V.A.; Lahr, F.A.R. 2019b. Evaluation of the Peltophorum vogelianum Benth. Wood Species for Structural Use. Eng Agr-Jaboticabal 39(6): 763-768. https://doi.org/10.1590/1809-4430-eng.agric.v39n6p763-768/2019.

Dadzie, P.K.; Amoah, M. 2015. Density, some anatomical properties and natural durability of stem and branch wood of two tropical hardwood species for ground applications. Eur J Wood Wood Prod 73(6): 759773. https://doi.org/10.1007/s00107-015-0925-x.

Fernandes, N.C.L.; Valle, M.L.A.; Calderon, C.M.A. 2018. Physical and anatomical characteristics of Cedrela odorata L. and Cedrelinga cateniformis Ducke. Floresta e Ambiente 25(1): 1-10. https://doi.org/10.1590/2179-8087.100814.

Icimoto, F.H.; Ferro, F.S.; Almeida, D.H.; Christoforo, A.L.; Lahr, F.A.R. 2015. Influence of specimen orientation on determination of elasticity in static bending. Maderas-Cienc Tecnol 17(2): 229-238. http://dx.doi.org/10.4067/S0718-221X2015005000022.

ISO. 2005. Structural timber - characteristic values of strength-graded timber - sampling, full-size testing and evaluation. ISO 13910. 2005. 30 p. Geneva, Switzerland.

Logsdon, N.B.; De Jesus, J.H.; Penna, J.E. 2010. Evaluation of the estimators of the characteristic strength to compression parallel to the grain. Sci For 38(88): 579-587. https://www.ipef.br/publicacoes/scien- 
tia/nr88/cap04.pdf.

Longui, E.L.; Pires, G.T.; Ballarin, A.W.; Machado, J.A.R. 2017. Shear strength parallel to grain with distinct ray orientation on four Brazilian wood species. Eur J Wood Wood Prod 75(4): 663-665. https://doi.org/10.1007/s00107-016-1129-8.

Matos, G.S.; Molina, J.C. 2016. Shear strength of wood in direction parallel to the grain according to the standards ABNT NBR 7190:1997 and ISO 13910:2005. Materia 21(4): 1069-1079. https://doi.org/10.1590/s1517-707620160004.0098.

NBR. 1997. Projeto de estruturas de madeira. NBR 7190. 1997. 107 p., Rio de Janeiro, Brazil.

Ruelle, J.; Beauchêne, J.; Yamamoto, H.; Thibaut, B. 2011. Variations in physical and mechanical properties between tension and opposite wood from three tropical rainforest species. Wood Sci Technol 45(2): 339-357. https://doi.org/10.1007/s00226-010-0323-9.

Segundinho, P.G.A.; Lahr, F.A.R.; Regazzi, A.J.; Carreira, M.R. 2015. Variation of modulus of elasticity obtained through the static bending method considering the $S / h$ ratio. Wood Res-Slovakia 60(2): 189-200. http://www.woodresearch.sk/wr/201502/02.pdf.

Silva, C.E.G.; Almeida, D.H.; Almeida, T.H.; Chahud, E.; Branco, L.A.M.N.; Campos, C.I.; Lahr, F.A.R, Christoforo, A.L. 2018. Influence of the procurement site on physical and mechanical properties of Cupiúba wood species. BioResources 13(2): 4118-4131. https://doi.org/10.15376/biores.13.2.4118-4131.

Silva, F.; Higuchi, N.; Matos, J.M.; Paula, E.M.; Santos, J. 2014. Nondestructive evaluation of hardness in tropical wood. J Trop For Sci 26(1): 69-74. https://www.jstor.org/stable/23617015.

Soriano, J.; Veiga, N.S.; Martins, I.Z. 2015. Wood density estimation using the sclerometric method. Eur J Wood Wood Prod 73(1): 753-758. https://doi.org/10.1007/s00107-015-0948-3.

Steege, H.; Vaessen, R.W.; Cárdenas-López, D.; Sabatier, D.; Antonelli, A.; Oliveira, S.M.; Pitman, N.C.A.; Jørgensen, P.M.; Salomão, R.P. 2016. The discovery of the Amazonian tree flora with an update checklist of all known tree taxa. Scientific Reports 6. https://doi.org/10.1038/srep29549.

Tenorio, C.; Moya, R. 2018. Evaluation of wood properties of four ages of Cedrela odorata trees growing in agroforestry systems with Theobroma cacao in Costa Rica. Agroforest Syst 93: 973-988. https://doi.org/10.1007/s10457-018-0194-x

Weerahandi, S. 1995. ANOVA under unequal error variances. Biometrics 51(2): 589-599. https://www.jstor.org/stable/2532947. 